\title{
Medullary and papillary carcinoma of the thyroid gland occurring as a collision tumor with lymph node metastasis: A case report
}

\author{
Mehr Sadat Alavi ${ }^{1}$ and Negar Azarpira ${ }^{2^{*}}$
}

\begin{abstract}
Introduction: Papillary thyroid carcinoma and medullary thyroid carcinoma are two different thyroid neoplasia. The simultaneous occurrence of medullary thyroid carcinoma and papillary thyroid carcinoma as a collison tumor with metastases from both lesions in the regional lymph nodes is a rare phenomenon.

Case presentation: A 32-year-old Iranian man presented with a fixed anterior neck mass. Ultrasonography revealed two separate thyroid nodules as well as a suspicious neck mass that appeared to be a metastatic lesion. The results of thyroid function tests were normal, but the preoperative calcitonin serum value was elevated. Our patient underwent a total thyroidectomy with neck exploration. Two separate and ill-defined solid lesions grossly in the right lobe were noticed. Histological and immunohistochemical studies of these lesions suggested the presence of medullary thyroid carcinoma and papillary thyroid carcinoma. The lymph nodes isolated from a neck dissection specimen showed metastases from both lesions.

Conclusions: The concomitant occurrence of papillary thyroid carcinoma and medullary thyroid carcinoma and the exact diagnosis of this uncommon event are important. The treatment strategy should be reconsidered in such cases, and genetic screening to exclude multiple endocrine neoplasia 2 syndromes should be performed. For papillary thyroid carcinoma, radioiodine therapy and thyroid-stimulating hormone suppressive therapy are performed. However, the treatment of medullary thyroid carcinoma is mostly radical surgery with no effective adjuvant therapy.
\end{abstract}

\section{Introduction}

Papillary thyroid carcinoma (PTC) and medullary thyroid carcinoma (MTC) are two different thyroid neoplasia. The former originates from thyroglobulin-producing follicular cells, whereas the latter arises from calcitoninproducing cells. MTC is a rare tumor that arises from neural crest-derived parafollicular $C$ cells. Tumors showing both features are rare and represent less than $1 \%$ of all thyroid malignancies [1] and have different patterns of clinical presentation and biological behavior. A review of the literature revealed similar lesions [1-11]. Mutations in the RET gene, rearrangements of the tyrosine kinase receptors RET (ret/PTC) and NTRK1, and point mutation of the BRAF gene have been

\footnotetext{
*Correspondence: negarazarpira@yahoo.com

2Department of Pathology, Organ Transplant Research Center, Shiraz

University of Medical Sciences, Shiraz, Iran

Full list of author information is available at the end of the article
}

documented in PTC tumors [12-15]. However, the exact pathogenesis of these cases is unknown, but an underlying genetic background has been hypothesized. In this report, a case of concurrent MTC and PTC has the features of a collision tumor.

\section{Case presentation}

A 32-year-old Iranian man was admitted for an anterior neck mass. He had no history of radiation to the head and neck and no known family history of endocrine disease. During a physical examination, his nodule was well demarcated, fixed, and measured about $2.5 \mathrm{~cm}$ in its largest diameter. An ultrasound examination of his neck showed a $3 \mathrm{~cm}$ solid hypoechoic nodule of the right thyroid lobe and an additional nodule in the lower pole of the same lobe. A suspicious neck mass that appeared to be metastatic lymph nodes was noticed. The left thyroid lobe and the isthmus appeared to be normal. Serum

\section{Biomed Central}


levels of free triiodothyronine, free thyroxine, and thyrotrophin were within normal ranges, and anti-thyroperoxidase/anti-thyroglobulin autoantibodies and antithyroglobulin antibody (anti- $\mathrm{Tg} \mathrm{Ab}$ ) were negative. A preoperative calcitonin serum value was elevated (40 $\mathrm{ng} /$ L) (chemiluminescence immunometric assay kit with reference intervals in adults: less than $11.5 \mathrm{ng} / \mathrm{L}$ for men and less than $4.6 \mathrm{ng} / \mathrm{L}$ for women). Our patient was screened for multiple endocrine neoplasia with negative results. He had normal serum levels of calcium, phosphorus, and parathyroid hormone. A chest X-ray and abdominal ultrasound were unremarkable. Fine needle aspiration of one nodule revealed papillary clusters that had atypical nuclei and intranuclear inclusions and that appeared to be a papillary carcinoma. Our patient underwent a total thyroidectomy with neck exploration. An enlarged thyroid gland with a prominent right lobe as well as a mottled lymph node in the right side were detected during the operation. Surgical specimens were fixed in $10 \%$ buffered formalin, embedded in paraffin, and stained with hematoxylin and eosin. For immunohistochemical studies, sections were incubated with the following primary monoclonal antibodies: cytokeratin AE1/AE3, chromogranin A, synaptophysin, thyroglobulin, and calcitonin (Dako Corporation, Glostrup, Denmark). An EnVision Dual Link systemHRP (ready to use; Dako Corporation) was used as a secondary antibody. Incubation with DAB (3,3'-diaminobenzidine tetrahydrochloride) was performed as a substrate chromogen solution to produce a brown color. All steps were carried out at room temperature. Appropriate positive and negative control sections were processed in parallel. An ill-defined, solid, tancolored lesion measuring $3 \mathrm{~cm}$ in its greatest diameter was observed grossly in the right lobe. In the same lobe, an irregular, whitish lesion measuring $1 \mathrm{~cm}$ in its greatest diameter was also present and was completely separated from the former lesion. The remaining thyroid tissue was unremarkable. A neck dissection yielded eight regional lymph nodes.

In light microscopy, two lesions had strikingly different morphologies. The largest nodule consisted of a sheet-like growth of cells with round nuclei and clumped chromatin with scant amphophilic cytoplasm (Figure 1). Mitotic activity was low, and no area of necrosis or hemorrhage was observed. The stroma contained a homogeneous and pink ground substance. There was no evidence of C-cell hyperplasia in the rest of the normal thyroid. Tumor cells were immunoreactive for calcitonin (Figure 2), chromogranin A, and synaptophysin and were negative for thyroglobulin and cytokeratin.

The lesion located in the lower pole of the same lobe showed a papillary growth pattern with nuclear

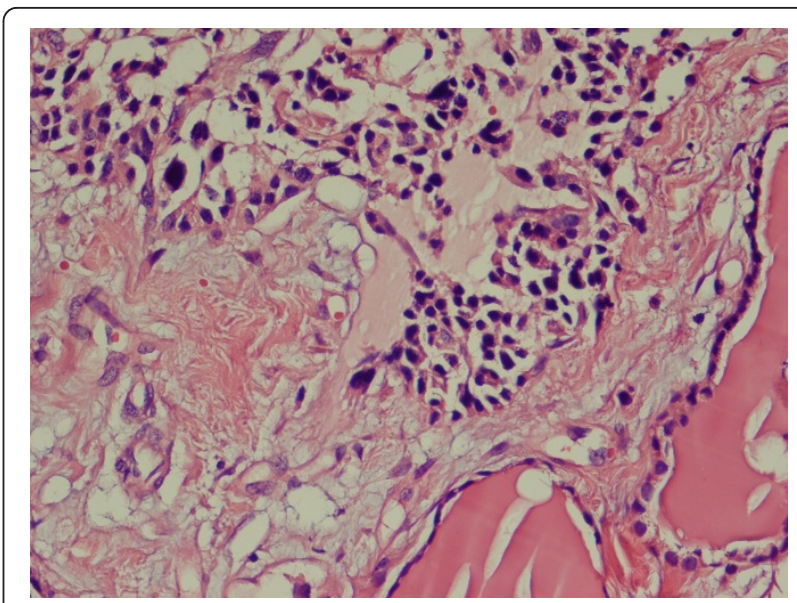

Figure 1 Sheet of polygonal cells with round to elongated nuclei and clumped chromatin embedded in amorphous eosinophilic material, adjacent to normal thyroid follicles (hematoxylin and eosin $[\mathrm{H} \& \mathrm{E}] \times 100$ ).

clearing, nuclear grooving, and occasional pseudoinclusions (Figure 3). These cells were immunoreactive for thyroglobulin and cytokeratin and were negative for calcitonin, chromogranin A, and synaptophysin. Four lymph nodes isolated from the neck dissection specimen showed metastasis of MTC, and one of them showed metastatic PTC. The stage of this tumor was T2N1M0. The result of a genetic analysis of RET oncogene was negative. For ablation of remnants of thyroid tissue, our patient received $150 \mathrm{mCi} \mathrm{I}^{131}$. Six months later, a whole-body scan with $\mathrm{I}^{131}$ was performed in order to find metastatic or active thyroid tissue, but the result was negative. Suppression therapy with thyroid hormone was performed; during followup, the serum levels of thyroglobulin (normal range is not more than $60 \mu \mathrm{g} / \mathrm{L}$ ), anti- Tg Ab (normal range is

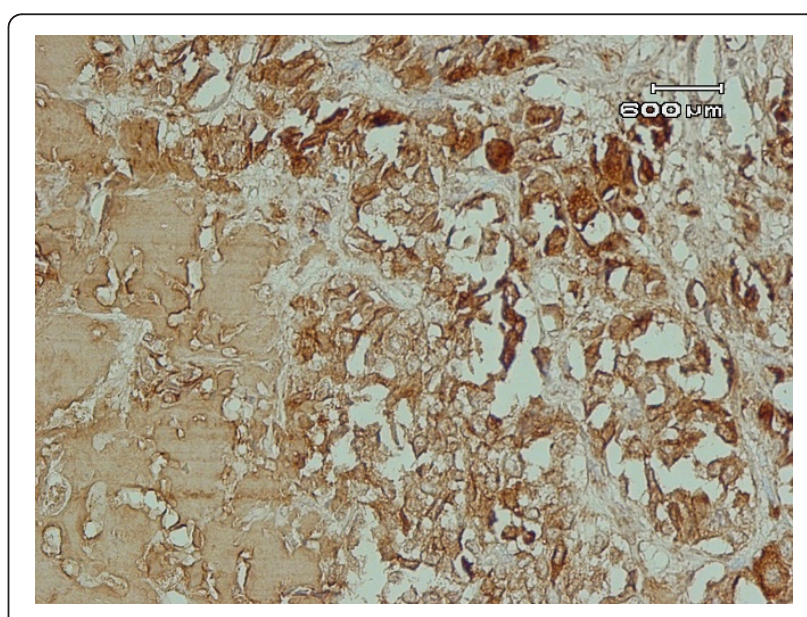

Figure 2 Polygonal cells show positive cytoplasmic immunostaining for calcitonin (immunohistochemistry $\times 100$ ) 


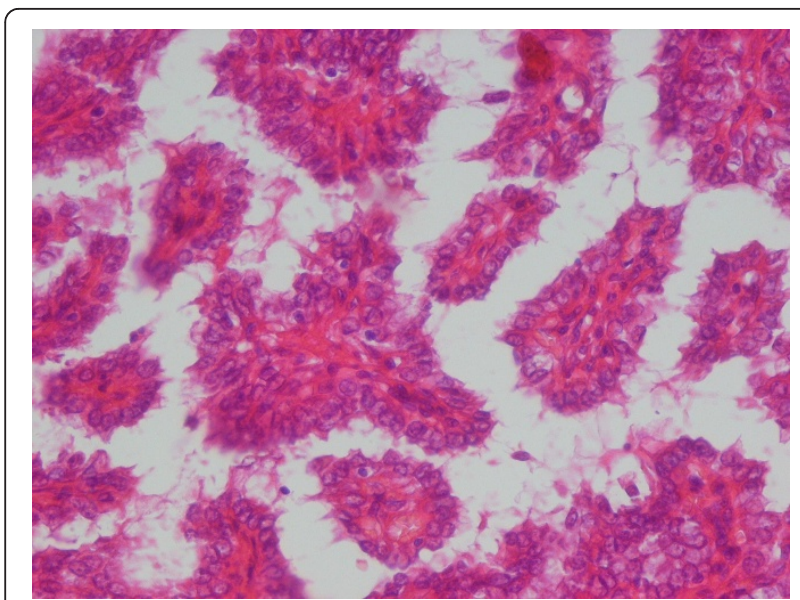

Figure 3 Papillary structure lined by cuboidal to columnar cells with eosinophilic cytoplasm and occasional nuclear inclusions (hematoxylin and eosin [H\&E] $\times 100$ ).

less than $2 \mathrm{IU} / \mathrm{mL}$ ), and calcitonin (normal range is less than $11.5 \mathrm{ng} / \mathrm{L}$ ) were routinely checked. The serum level was undetectable after surgery, and no increase in these parameters was detected. Our patient is clinically well 12 months after surgery.

\section{Discussion}

The simultaneous occurrence of MTC and PTC in the same thyroid is a rare phenomenon that can be observed in two main settings: a mixed tumor showing dual differentiation [15] or a collision tumor (that is, a tumor with two separate and different components) [2-8]. Our case belongs to the latter category since lesions with features of MTC and PTC were detected in two different locations and separated by normal thyroid tissue.

Histopathology and immunohistochemical findings of the first nodule suggested that it was a small-cell variant of MTC. Histopathology and immunohistochemical findings of these nodules were small-cell variants of MTC and papillary microcarcinoma according to the current World Health Organization classification of thyroid tumors.

Our strategy in the treatment of thyroid carcinoma is similar to guidelines used in Western countries [16]. All patients were routinely examined by preoperative ultrasonography to estimate intrathyroid spread of the tumor. In patients with clinically involved lateral cervical lymph nodes detected by ultrasonography or computed tomography, a modified radical neck dissection was performed. For evaluation of bone and distant metastases, radioactive iodine whole-body scanning was done. Before radioactive iodine scanning, any thyroxin treatments were discontinued for four weeks and patients were placed under strict restriction of iodine-containing food for two weeks. Postoperative radioiodine therapy and thyroid-stimulating hormone suppressive therapy were performed. During follow-up, the serum levels of thyroglobulin, anti-Tg Ab, and calcitonin were routinely checked.

The coexistence of PTC and MTC has been reported in the literature [1-11]. These tumors occurred together more frequently in women, presented with a palpable neck mass, and were treated with surgery. Metastatic foci of either PTC or MTC were detected in few patients $[4,6,7]$. These lymph node metastases show pure tumor cell populations of one or two components or an admixture of both components within the same lymph node $[9,17]$. Distant metastases were described mostly in the mediastinum, lung, liver, and bone [18]. Fugazzola and colleagues [3] reported the familial clustering for these types of tumors, but the exact pathogenesis of these thyroid malignancies is completely unknown. Genetic analysis of RET oncogene in reported cases had conflicting results. Brauckhoff and colleagues [19] and Papi and colleagues [20] reported that germline point mutation of the RET gene had a potential role in the development of both MTC and PTC. However, according to Cerrato and colleagues [21], half of sporadic MTCs do not carry RET mutations and other genes, such as RB (retinoblastoma) and TP53 tumor suppressor pathways, may be involved in MTC formation. Rossi and colleagues [1] reported that both the RET and BRAF genes had a role in the genesis of the medullary-papillary collision tumors. The RET proto-oncogene plays a key role in the development of MTC. Vantyghem and colleagues [10] reported 11 cases of familial MTC-PTC according to clinical, histologic, or family features (or a combination of these features), but no RET defects were present. The authors suggested that another gene or uncommon abnormality of the RET gene was responsible for tumorgenesis. A recent animal study by Miller and colleagues $[22,23]$ suggested that the PI3K or Ras signaling cascade alone was unable to transform thyroid follicular cells but that simultaneous activation had invasive and metastatic potential. Overall, the molecular evidence suggested that the two components of these heterogeneous groups of tumors were not derived from a common stem cell $[23,24]$. The origin of each carcinoma is embryologically different because the $\mathrm{C}$ cells stem from an ultimobranchial body that derived from the fourth pharyngeal pouch, whereas the thyroglobulin and thyroid hormone-producing cells come from the follicular epithelial cells derived from a median endodermal anlage from the tongue.

\section{Conclusions}

In this case, the simultaneous occurrence of MTC and PTC presented as two distinct and well-defined tumor 
components. MTC shows a wide spectrum of morphological variants that resemble follicular, papillary, and undifferentiated carcinoma. The immunohistochemical studies for calcitonin along with thyroglobulin negativity usually confirm the C-cell origin of tumor cells. Overall, mixed MTC-PTC is a rare clinical entity and should be considered in the differential diagnosis of thyroid tumors, particularly in patients with a family history of thyroid malignancy.

\section{Consent}

Written informed consent was obtained from the patient for publication of this case report and any accompanying images. A copy of the written consent is available for review by the Editor-in-Chief of this journal.

\section{Abbreviations}

Anti-Tg Ab: anti-thyroglobulin antibody; MTC: medullary thyroid carcinoma; PTC: papillary thyroid carcinoma.

\section{Author details \\ ${ }^{1}$ Department of Nuclear Medicine, Shiraz University of Medical Sciences, Shiraz, Iran. ${ }^{2}$ Department of Pathology, Organ Transplant Research Center Shiraz University of Medical Sciences, Shiraz, Iran.}

\section{Authors' contributions}

NA participated in histology-related issues and literature review and drafted the manuscript. MSA contributed to patient treatment and revised respective sections in the manuscript. Both authors read and approved the final manuscript.

\section{Competing interests}

The authors declare that they have no competing interests.

Received: 21 September 2009 Accepted: 20 December 2011 Published: 20 December 2011

\section{References}

1. Rossi S, Fugazzola L, De Pasquale L, Braidotti P, Cirello V, Beck-Peccoz P, Bosari S, Bastagli A: Medullary and papillary carcinoma of the thyroid gland occurring as a collision tumour: report of three cases with molecular analysis and review of the literature. Endocr Relat Cancer 2005, 12:281-289.

2. Darwish A, Satir AA, Hameed T, Malik S, Agel N: Simultaneous medullary carcinoma, occult papillary carcinoma and lymphocytic thyroiditis. Malays J Pathol 1995, 17:103-107.

3. Fugazzola L, Cerutti N, Mannavola D, Ghilardi G, Alberti L, Romoli R, BeckPeccoz P: Multigenerational familial medullary thyroid cancer (FMTC): evidence for FMTC phenocopies and association with papillary thyroid cancer. Clin Endocrinol (Oxf) 2002, 56:53-63.

4. Gero MJ, Lipper S, Chernys AE, Silver L: Medullary and papillary carcinomas occurring as a collision tumor: report of a case. Clin NuCl Med 1989, 14:171-174.

5. Gonzalez-Campora R, Lopez-Garrido J, Martin-Lacave I, Miralles-Sanchez EJ, Villar JL: Concurrence of a symptomatic encapsulated follicular carcinoma, an occult papillary carcinoma and a medullary carcinoma in the same patient. Histopathology 1992, 21:380-382.

6. Ishida T, Kawai T, lino Y, Shinozaki K, Oowada S, Izuo M: Concurrent medullary carcinoma adjacent to papillary carcinoma of the thyroid, a clinicopathological and electron microscopic study. Gan No Rinsho 1985 31:1814-1820.

7. Kobayashi K, Teramoto S, Maeta H, Ishiguro S, Mori T, Horie $Y$ : Simultaneous occurrence of medullary carcinoma and papillary carcinoma of the thyroid. J Surg Oncol 1995, 59:276-279.
8. Lamberg BA, Reissel P, Stenman S, Ekblom A, Makinen J, Franssila K: Concurrent medullary and papillary thyroid carcinoma in the same thyroid lobe and in siblings. Acta Med Scand 1981, 209:421-424.

9. Lax SF, Beham A, Kronberger-Schonecker D, Langsteger W, Denk H: Coexistence of papillary and medullary carcinoma of the thyroid gland mixed or collision tumour? Clinicopathological analysis of three cases. Virchows Arch 1994, 424:441-447.

10. Vantyghem MC, Pigny P, Leteurtre E, Leclerc L, Bauters C, Douillard C, D'Herbomez M, Carnaille B, Proye C, Wemeau JL, Lecomte-Houcke M: Thyroid carcinomas involving follicular and parafollicular $C$ cells: seventeen cases with characterization of RET oncogenic activation. Thyroid 2004, 14:842-847.

11. Pastolero GC, Coire Cl, Asa SL: Concurrent medullary and papillary carcinomas of thyroid with lymph node metastases. A collision phenomenon. Am J Surg Pathol 1996, 20:245-250.

12. Younes N, Shomaf M, Al Hassan L: Simultaneous medullary and papillary thyroid carcinoma with lymph node metastasis in the same patient: case report and review of the literature. Asian J Surg 2005, 28:223-226.

13. Kimura ET, Nikiforova MN, Zhu Z, Knauf JA, Nikiforov YE, Fagin JA: High prevalence of BRAF mutations in thyroid cancer: genetic evidence for constitutive activation of the RET/PTC-RAS-BRAF signaling pathway in papillary thyroid carcinoma. Cancer Res 2003, 63:1454-1457.

14. Alberti L, Carniti C, Miranda C, Roccato E, Pierotti MA: RET and NTRK1 proto-oncogenes in human diseases. J Cell Physiol 2003, 195:168-186.

15. Marsh DJ, Learoyd DL, Andrew SD, Krishnan L, Pojer R, Richardson AL, Delbridge L, Eng C, Robinson BG: Somatic mutations in the RET protooncogene in sporadic medullary thyroid carcinoma. Clin Endocrinol (Oxf) 1996, 44:249-257.

16. Sugitani I, Kasai N, Fujimoto $Y$, Yanagisawa A: A novel classification system for patients with PTC: addition of the new variables of large $(3 \mathrm{~cm}$ or greater) nodal metastases and reclassification during the follow-up period. Surgery 2004, 135:139-148

17. Mizukami Y, Nonomura A, Michigishi T, Noguchi M, Ishizaki T: Mixed medullary-follicular carcinoma of the thyroid gland: a clinicopathologic variant of medullary thyroid carcinoma. Mod Pathol 1996, 9:631-635.

18. Papotti M, Negro F, Carney JA, Bussolati G, Lloyd RV: Mixed medullaryfollicular carcinoma of the thyroid. A morphological, immunohistochemical and in situ hybridization analysis of 11 cases. Virchows Arch 1997, 430:397-405.

19. Brauckhoff M, Gimm O, Hinze R, Ukkat J, Brauckhoff K, Dralle H: Papillary thyroid carcinoma in patients with RET proto-oncogene germline mutation. Thyroid 2002, 12:557-561.

20. Papi G, Corrado S, Pomponi MG, Carapezzi C, Cesinaro A, LiVolsi VA: Concurrent lymph node metastases of medullary and papillary thyroid carcinoma in a case with RET oncogene germline mutation. Endocr Pathol 2003, 14:269-276.

21. Cerrato A, De Falco V, Santoro M: Molecular genetics of medullary thyroid carcinoma: the quest for novel therapeutic targets. J Mol Endocrinol 2009, 43:143-155.

22. Miller KA, Yeager N, Baker K, Liao XH, Refetoff S, Di Cristofano A: Oncogenic Kras requires simultaneous $\mathrm{PI} 3 \mathrm{~K}$ signaling to induce ERK activation and transform thyroid epithelial cells in vivo. Cancer Res 2009, 69:3689-3694.

23. Nangue C, Bron L, Portmann L, Volante M, Ris HB, Monnier P, AndrejevicBlant S: Mixed medullary-papillary carcinoma of the thyroid: report of a case and review of the literature. Head Neck 2009, 31:968-974.

24. Volante M, Papotti M, Roth J, Saremaslani P, Speel EJ, Lloyd RV, Carney JA, Heitz PU, Bussolati G, Komminoth P: Mixed medullary-follicular thyroid carcinoma. Molecular evidence for a dual origin of tumor components. Am J Pathol $1999,155 \cdot 1499-1509$.

doi:10.1186/1752-1947-5-590

Cite this article as: Sadat Alavi and Azarpira: Medullary and papillary carcinoma of the thyroid gland occurring as a collision tumor with lymph node metastasis: A case report. Journal of Medical Case Reports 2011 5:590. 